\title{
The association between serum levels of growth differentiation factor-15 and rheumatoid arthritis activity
}

\author{
Kamal Esalatmanesh ${ }^{1}$, Hamidreza Fayyazi ${ }^{1}$, Roozbeh Esalatmanesh ${ }^{1}$, and Alireza \\ Khabbazi $^{2}$ \\ ${ }^{1}$ Autoimmune Diseases Research Center, Kashan University of Medical Sciences \\ ${ }^{2}$ Affiliation not available
}

April 28, 2020

\begin{abstract}
Background: Macrophages play a crucial role in the pathogenesis of rheumatoid arthritis (RA). Growth differentiation factor-15 (GDF-15) acts as an autocrine regulator of macrophage activation. Objective: The aim of this study was to assess serum level of GDF-15 as a potential biomarker for detecting RA activity. Method: A total of 100 female RA patients and 55 age matched healthy control females were enrolled. The serum level of GDF-15 was measured using enzyme-linked immunosorbent assay by an eBioscience kit. Results: Serum levels of GDF-15 in RA patients with high, moderate, low and no disease activity were $989.0 \pm 161.9,505.6 \pm 220.5,349.2 \pm 155.9$ and $349.0 \pm 144.0 \mathrm{pg} / \mathrm{ml}$, respectively. GDF-15 with a cut-off value higher than 705 $\mathrm{pg} / \mathrm{ml}$ was indicative of high RA activity with sensitivity of $96 \%$ and specificity of $92 \%$. Conclusion: GDF-15 serum levels may be used as a biomarker to predict high RA disease activity.
\end{abstract}

\section{Title page}

The association between serum levels of growth differentiation factor-15 and rheumatoid arthritis activity

Running title: GDF-15 in rheumatoid arthritis

Esalatmanesh $\mathrm{K}^{1}$, Fayyazi $\mathrm{H}^{1}$, Esalatmanesh $\mathrm{R}^{1}$, Khabbazi ${ }^{2 *}$

${ }^{1}$ Autoimmune Diseases Research Center, Kashan University of Medical Sciences, Kashan, Iran

${ }^{2}$ Connective Tissue Diseases Research Center, Tabriz University of Medical Sciences, Tabriz, Iran

\section{Authors:}

Kamal Esalatmanesh: Autoimmune Diseases Research Center, Kashan University of Medical Sciences, Kashan, Iran. Email: kamal.esalat@yahoo.com

Hamidreza Fayyazi: Autoimmune Diseases Research Center, Kashan University of Medical Sciences, Kashan, Iran. Email: hamidreza.fayyazi@yahoo.com

Roozbeh Esalatmanesh: Autoimmune Diseases Research Center, Kashan University of Medical Sciences, Kashan, Iran. Email: esalatr@gmail.com

Alireza Khabbazi: Connective Tissue Diseases Research Center, Tabriz University of Medical Sciences, Tabriz, Iran. E-mail: dr_khabbazi@yahoo.com

*Corresponding Author 
Alireza Khabbazi, MD.

Address: Connective Tissue Diseases Research Center, Flat 4, Emamreza Hospital, Tabriz University of Medical Sciences, Golgasht St., P.O Box 5166614756, Tabriz, Iran.

E-mail: dr_khabbazi@yahoo.com

Tel: +984133369331

\section{Acknowledgments}

We thank all the participants of this study who contributed with us.

\section{Hosted file}

Final GDF.docx available at https://authorea.com/users/313867/articles/444271-the-associationbetween-serum-levels-of-growth-differentiation-factor-15-and-rheumatoid-arthritis-activity
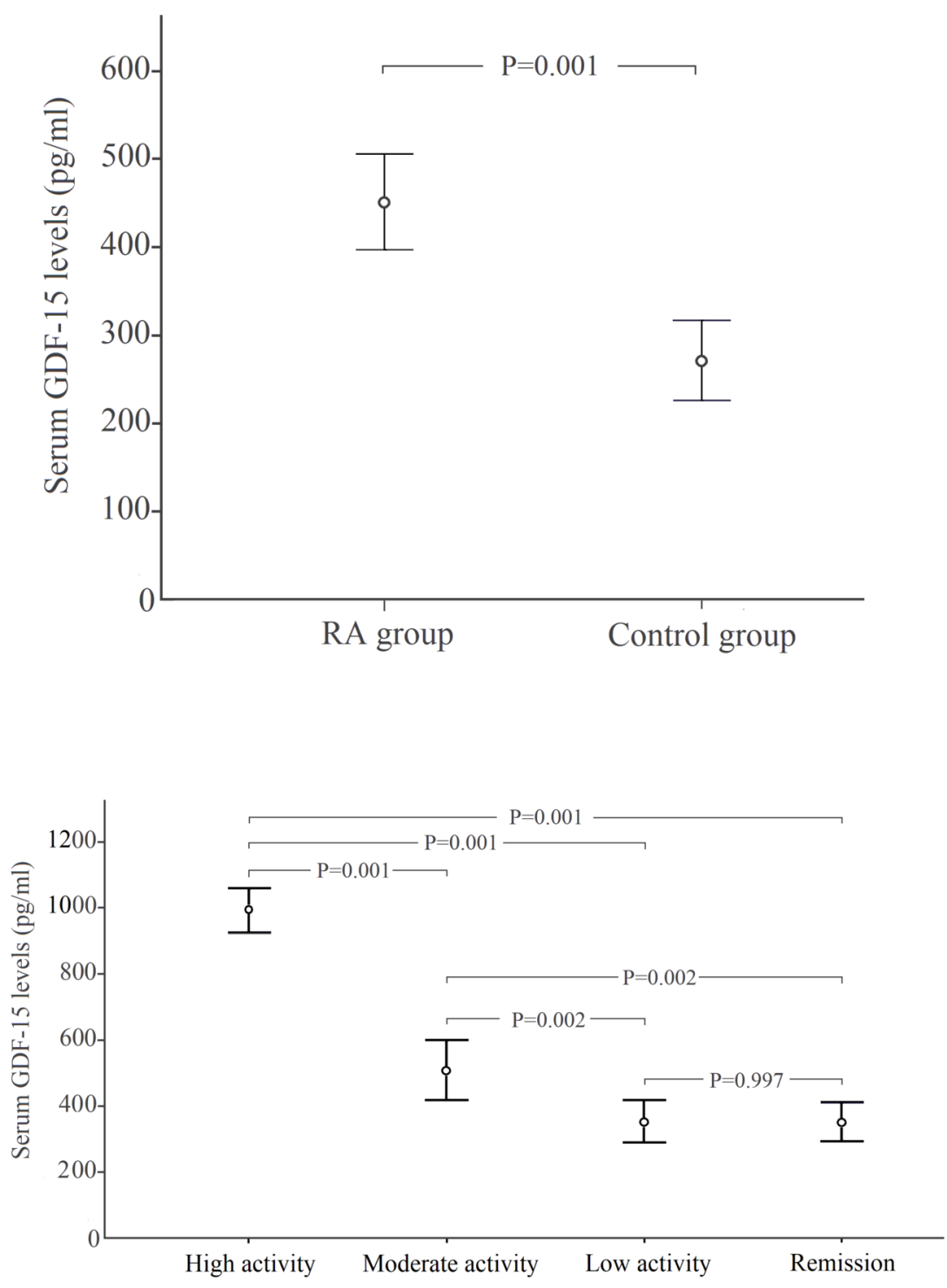

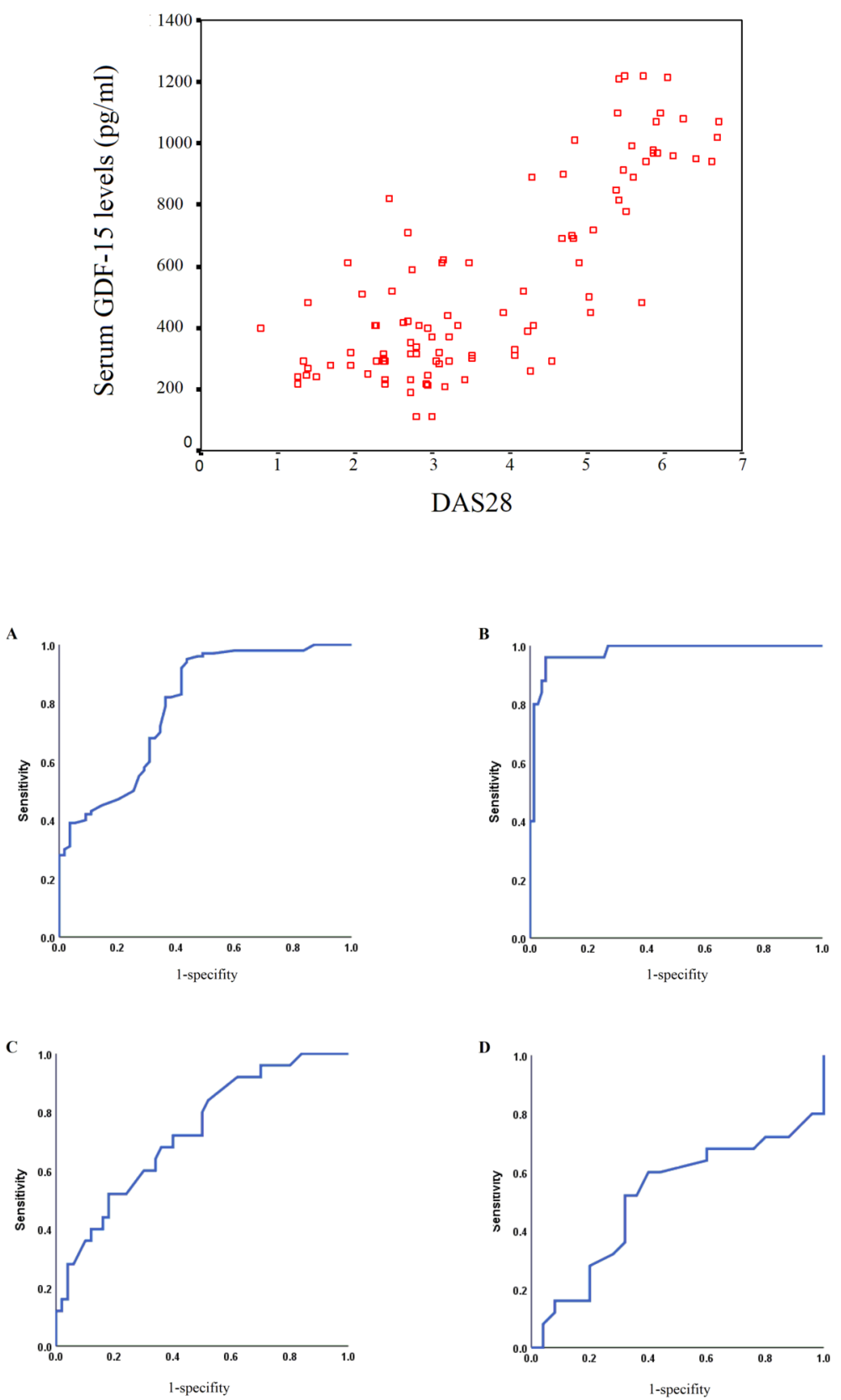

\section{Hosted file}

Table 1.docx available at https://authorea.com/users/313867/articles/444271-the-associationbetween-serum-levels-of-growth-differentiation-factor-15-and-rheumatoid-arthritis-activity 